\title{
Hasil Tangkapan Rajungan (Portunus pelagicus) dengan Menggunakan Alat Tangkap Bubu Lipat yang Didaratkan di TPI Tanjung Sari Kabupaten Rembang
}

\author{
Anthonius Hot Arios, Anhar Solichin, Suradi Wijaya Saputra *) \\ Jurusan Perikanan Fakultas Perikanan dan Ilmu Kelautan Universitas Diponegoro \\ Jl. Prof. Soedharto, SH Semarang
}

\begin{abstract}
Abstrak
Bubu merupakan jenis alat tangkap ikan yang dioperasikan secara pasif di dasar perairan. Secara umum bubu dapat digolongkan sebagai alat penangkap yang berbentuk seperti kurungan atau berupa ruangan tertutup dimana ikanikan tidak dapat keluar lagi. Materi yang digunakan dalam penelitan adalah alat tangkap bubu lipat dan rajungan hasil tangkapan diukur berat untuk analisis struktur ukuran berat,produksi harian untuk menganalisis CPUE harian. Materi tersebut di dapat dari hasil melaut selama 1 bulan di Perairan Jawa Kabupaten Rembang. Metode yang digunakan dalam Penelitian ini adalah dengan metode deskriptif dan metode pengambilan sampel yang digunakan adalah sistematik random sampling. Tujuan dari penelitian ini adalah mengetahui jumlah, jenis, dan kelimpahan rajungan yang tertangkap dengan alat tangkap bubu lipat di TPI Tanjung Sari,Rembang, mengetahui Catch Per Unit Effort (CPUE) rajungan dengan menggunakan alat tangkap bubu lipat di TPI Tanjung Sari, mengetahui strukur ukuran berat rajungan dengan menggunakan bubu lipat, mengetahui status atau tingkat pemanfaatan optimal produksi rajungan harian per satuan upaya penangkapan (CPUE). Dari hasil penelitian didapatkan bahwa spesies rajungan yang didapat selama penelitian adalah Portunus sp. produksi alat tangkap bubu rajungan sebesar 591,76 kg, struktur ukuran berat dan frekuensi rajungan yang tertangkap dengan bubu didominasi oleh kelas kelas 161.1-187.9 gr yaitu frekuensi sebanyak 736 ekor dan terendah oleh kelas 300-326.8 gr dengan jumlah frekuensi sebanyak 27 ekor rajungan ,dan CPUE yang tertinggi pada hari ke-26 yaitu sebanyak $5,75 \mathrm{~kg} /$ trip dengan total dan CPUE terendah terjadi pada hari ke-7 yaitu sebesar 4,22 kg/trip dengan CPUE rata-rata 4,55 kg/tri dengan rata-rata total produksi 19,73kg/hari dan rata-rata CPUE 3,95kg/trip/hari. Dalam penyusunan konsep pengelolaan perlu diadakan pendataan produksi dan trip hasil tangkapan bubu sehingga perkembangan eksploitasinya dapat terus di pantau pada setiap tahunnya.
\end{abstract}

Kata kunci : Bubu, Rajungan, Analisis CPUE, Struktur ukuran berat, Perairan Rembang

\section{Fishing Result Analysis of Rajungan (Portunus pelagicus) by Using Folded Bubu as A Fishing Gear That was Done in TPI Tanjung Sari, Rembang}

Anthonius Hot Arios, Anhar Solichin, Suradi Wijaya Saputra *)

\begin{abstract}
Trap or bubu is a fishing gear that operated passively in waters at the base of sand. Commonly bubu can be clasified as a fishing gear shaped like a confinement or a closed room when fishes can't go out anymore. The material that was used in this research is folded bubu as a fishing gear and rajungan (Portunus pelagicus) as a fishing result is measured weight to analize weight structure, daily production to analize daily CPUE. That material was gotten from fishing result in 1 month at Java Sea in Rembang Regency. The method was used in this research is descriptive method and the method of taking sample that was used is random sampling systematic The purpose of this research method is to make a description of amount, species, and the abundance of small crab that caught with folded bubu as a fishing gear in TPI Tanjung Sari, Rembang, to know Catch per unit Effort (CPUE) rajungan (Portunus pelagicus) by using folded bubu, to know the status or level of the optimal daily rajungan (Portunus pelagicus) utilization per unit the catching effort (CPUE). From this research results we can conclude that rajungan (Portunus pelagicus) species gotten during this research is called Portunus sp. The production of bubu as a fishing gear to catch rajungan (Portunus pelagicus) is $591,76 \mathrm{~kg}$, the structure of weight measure and the frequency of rajungan (Portunus pelagicus) that was caught with bubu is dominated by the class/level of $161.1-187.9 \mathrm{gr}$ that the frequency amount is 736 and the lowest is by the class/level of $300-326.8$ gr with the frequency amount is 27 rajungan (Portunus pelagicus), and the highest CPUE on the 26th day is $5,75 \mathrm{~kg} /$ trip with the total and the lowest CPUE was occured on the 27 th day that is 4,22 $\mathrm{kg} /$ trip with the average CPUE is $4,55 \mathrm{~kg} /$ trip with the average of total production is $19,73 \mathrm{~kg} / \mathrm{day}$ and the average of CPUE is $3,95 \mathrm{~kg} /$ trip/day. The conclusion that can be given to arrange the concept of management that can be given, the production logging and the results of catching by bubu trip is needed, so the exploitation development can be monitored on each year.
\end{abstract}

Keywords : Bubu, Rajungan (Portunus pelagicus), Analysis CPUE, Weight analysis structure, Rembang Waters 


\section{PENDAHULUAN}

Wilayah pesisir adalah wilayah pertemuan antara daratan dan lautan, dimana merupakan aset bangsa Indonesia yang sangat menjanjikan untuk pengelolaan secara ekonomi dengan menggunakan jasa lingkungan (environmental services), diantaranya jasa ilmu perikanan yang sangat potensial bagi kepentingan pembangunan dan kelangsungan hidup manusia. Usaha yang dilakukan secara langsung mengarah pada usaha yang mengancam sumberdaya pesisir, karena bersifat eksploratif yang berlebihan untuk mendapatkan hasil yang sebanyakbanyaknya.

Sumberdaya alam yang ada sekarang ini belum dimanfaatkan secara bijaksana dan kurang memperhatikan kelestariannya. Masyarakat pesisir dapat memanfaatkan sumberdaya tersebut sebagai tempat usaha baik yang secara langsung maupun tidak langsung. Akan tetapi kegiatan-kegiatan tersebut harus diimbangi dengan usahausaha yang sifatnya konservatif. Hal ini bertujuan agar pemanfaatan sumberdaya yang ada akan tetap lestari. Selain mempunyai hak untuk mengelola atau menggunakan sumberdaya, kita juga mempunyai kewajiban untuk menjaga sumberdaya agar sumberdaya tersebut dapat terus termanfaatkan dalam waktu yang sangat lama atau secara berkelanjutan. Oleh karena itu partisipasi masyarakat secara langsung maupun tidak langsung dapat membantu pemerintah dalam mendukung terpeliharanya konservasi sumberdaya alam.

Pengelolaan sumberdaya pesisir yang dilakukan jika tanpa arahan dan rancangan kebijakan yang benar, maka akan mengurangi tingkat keberhasilan suatu usaha. Mengingat pemanfaatan sumberdaya di Indonesia yang bersifat open access maka peraturan tentang pemakaian alat tangkap dan lain sebagainya masih kurang teratur. Akan tetapi sebaliknya apabila pemanfaatan sumberdaya alam secara optimal dengan tetap mempertahankan kelestarian sumberdaya alam merupakan salah satu landasan pemikiran bagi keberlanjutan pembangunan.

Perikanan merupakan salah satu bidang yang diharapkan mampu menjadi penopang kesehjahteraan rakyat Indonesia. Sub sektor perikanan dapat berperan dalam pemulihan dan pertumbuhan perekonomian bangsa Indonesia karena potensi sumberdaya ikan yang besar dalam jumlah dan keragamannya. Selain itu, sumberdaya ikan termasuk sumberdaya yang dapat diperbaharui (renewable resources) sehingga dengan pengelolaan yang bijaksana, dapat terus dinikmati manfaatnya.

Kegiatan perikanan tangkap khususnya di pesisir pantai sampai saat ini masih menjadi alternatif utama penangkapan ikan bagi sebagian besar nelayan Indonesia. Dari total armada penangkapan yang ada, kurang lebih 90\%-nya adalah perikanan skala kecil yang terkonsentrasi di daerah pantai. Minimnya modal dan teknologi penangkapan serta melimpahnya sumberdaya ikan di daerah pantai mendorong nelayan untuk melakukan aktivitas di sana (Monintja, 2006).

Pemanfaatan sumberdaya perikanan, khusus tangkap sampai saat ini masih didominasi oleh usaha kecil, aplikasi teknologi yang masih sederhana, jangkauan penangkapan yang terbatas di sekitar pantai, dan produktivitas yang relatif masih rendah. Produktivitas nelayan yang rendah umumnya diakibatkan oleh rendahnya keterampilan dan pengetahuan serta penggunaan alat tangkap maupun perahu yang masih sederhana sehingga efektifitas efisiensi alat tangkap dan penggunaan faktor - faktor produksi produksi lainnya belum optimal. Keadaan ini sangat berpengaruh terhadap pendapatan yang diterima oleh nelayan dan akhirnya mempengaruhi pula pada tingkat kesejahteraan para nelayan,mengapa dapat berpengaruh,karna Dalam melaksanakan kegiatannya nelayan sangat bergantung pada factor-faktor produksi (input) yang pada berberapa tahun terakhir mengalami kenaikan harga sehingga dengan hasil tangkapan yang cenderung tidak pasti, menyebabkan pendapatan para nelayan juga menurun.

Selain itu juga penggunaan alat tangkap perikanan yang sembarangan dan tidak memperhatikan aspek biologis ikut berperan dalam penurunan hasil tangkapan ikan. Faktor-faktor produksi tersebut antara lain tenaga kerja, bahan bakar, boat (perahu), dan gear (alat tangkap).

Tujuan dari penelitian ini adalah mengetahui jumlah, jenis, dan kelimpahan rajungan yang tertangkap dengan alat tangkap bubu lipat di TPI Tanjung Sari,Rembang, mengetahui Catch Per Unit Effort (CPUE) rajungan dengan menggunakan alat tangkap bubu lipat di TPI Tanjung Sari, mengetahui strukur ukuran berat rajungan dengan menggunakan bubu lipat, mengetahui status atau tingkat pemanfaatan optimal produksi rajungan harian per satuan upaya penangkapan (CPUE).

\section{MATERI DAN METODE}

Penelitian ini dilaksanakan pada bulan April 2012 dengan lokasi di TPI Tanjung Sari, Kabupaten Rembang Jawa tengah. Metode yang digunakan dalam penelitian ini adalah metode penelitian deskriptif yaitu penelitian yang dilakukan pada waktu, tempat, dan populasi yang terbatas sehingga dapat memberikan gambaran situasi dan kondisi secara sistematis, faktual dan akurat mengenai fakta-fakta dan sifat-sifat populasi daerah tertentu.

Data yang digunakan dalam penelitian ini berasal dari data primer. Data primer adalah data yang didapatkan secara langsung dari objek penelitian yaitu dengan observasi atau pengamatan secara langsung dan dokumentasi. Pengambilan sampel dilakukan dengan sistematik random sampling, yaitu pengambilan sampel secara sistematik pada suatu populasi. Sistematik maksudnya adalah sampel diambil pada tempat yang sama, 
dalam waktu yang sama setiap harinya, sampel didapat dari hasil tangkapan selama melaut, dalam selang waktu selama satu bulan. Lokasi pengambilan sampel di Tempat Pelelangan Ikan yaitu di TPI Tanjung Sari. Pengambilan sampel dilakukan di tempat tersebut karena TPI ini merupakan tempat dimana para nelayan bubu lipat menjual rajungan hasil tangkapan.

Untuk memperoleh data produksi harian maka kegiatan pengambilan sampel dilakukan setiap hari dalam jangka waktu 30 hari di TPI Tanjung Sari Kabupaten Rembang,data rajungan hasil tangkapan bubu lipat di dapat kan dari 5 kapal yang beroperasi, lalu rajungan hasil tangkapan dijumlahkan setiap harinya.

Analisis CPUE, menggambarkan jumlah hasil tangkapan yang tertangkap. Setelah itu dilakukan dilakukan pengukuranberat hasil tangkapan untuk mengetahui ukuran rata-rata berat hasil tangkapan yang tertangkap di TPI Tanjung Sari, Kabupaten Rembang.

Produktivitas per trip, dilakukan untuk melihat produktivitas per trip penangkapan dari masing-masing alat tangkap. Cara menghitungnya dengan membagi jumlah penangkapan atau rata-rata produksi dan rata-rata jumlah trip penangkapan dari masing-masing alat tangkap. Di ukur dengan satuan kg/trip. Menurut Saputra (2009), untuk menghitung Catch Per Unit Effort (CPUE) alat tangkap, dengan rumus :

$$
\mathrm{CPUE}=\frac{\text { Produksi }}{\text { kapal }} \text { atau } \mathrm{CPUE}=\frac{\text { Produksi }}{\text { trip }}
$$

\section{HASIL DAN PEMBAHASAN}

\section{Deskripsi Lokasi Penelitian}

Kabupaten Rembang memiliki potensi perikanan dan kelautan yang sangat besar, hal ini ditandai dengan panjang wilayah pantai Kabupaten Rembang sepanjang $\pm 62,33 \mathrm{Km}$ yang banyak terkandung berbagai potensi hasil laut yang melimpah yaitu dengan jenis yang dominan adalah ikan layang, tambang, kembung, selar, tongkol, cumi-cumi, kurisi, teri, manyung, layur, kakap, dan rajungan. Kabupaten Rembang secara geografis terletak antara $111^{\circ} 00^{\prime}-111^{\circ} 30^{\prime} \mathrm{BT}$ dan $6^{\circ} 30^{\prime}-7^{\circ} 00^{\prime} \mathrm{LS}$. Adapun batas- batasnya antara lain:

Sebelah Barat : Kabupaten Pati

Sebelah Utara : Laut Jawa

Sebelah Timur : Kabupaten Tuban

Sebelah Selatan : Kabupaten Blora

Penelitian ini dilakukan dengan mengambil 5 titik pengamatan dimana Titik I pada koordinat

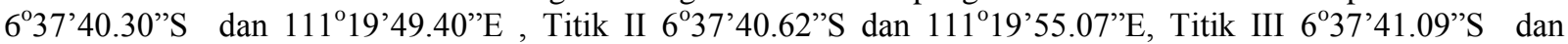

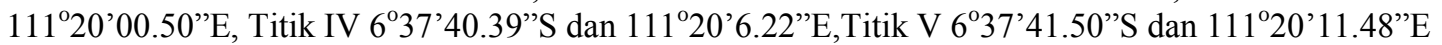

Sistem penangkapan bubu yang digunakan oleh nelayan yaitu pengoperasian bubu pada sistem rawai yaitu bubu dipasang dalam jumlah banyak dan dirangkai menggunakan tali antara bubu satu dengan bubu lainnya. Biasanya bubu yang dipasang dengan sistem rawai biasanya dihubungkan dengan pengait (snap) antara tali cabang dan tali utama. Kemudian ditandai dengan pelampung tanda pada kedua ujungnya dan dilengkapi pemberat agar bubu tidak berpindah tempat. Sebelum meletakkan bubu biasa para nelayan menentukan letak pencarian derah tangkapan ikan( fishing ground), tahap pencarian daerah penangkapan ikan (fishing ground) umumnya dilakukan berdasarkan pada kedalaman, kebisaaan dan pengalaman nelayan dalam melakukan operasi penangkapan, umumnya lokasi pemasangan bubu berada pada perairan sekitar pantai terbuka yang dipengaruhi gelombang, kecepatan arus tidak terlalu besar, dasar perairan berupa pasir, pasir berlumpur dan lumpur, setelah menemukan daerah penangkapan biasanya nelayan melakukan peletakkan bubu yang dilakukan pada saat pagi hari dan dibiarkan semalam, sedangkan pengambilan hasil tangkapan bubu dilakukan pada pagi hari berikutnya. Namun ada beberapa nelayan yang meninggalkan atau merendam bubunya selama dua hari atau lebih. Hal tersebut tergantung dari keadaan laut. Jika ombak atau gelombang cukup besar maka nelayan lebih memilih untuk tidak mengangkat bubu dan menunggu sampai keadaan laut memungkinkan untuk melakukan penarikan jaring.

Umpan merupakan salah satu faktor yang mempengaruhi keberhasilan penangkapan dengan menggunakan bubu. Umpan berperan sebagai salah satu bentuk pemikat yang memberikan rangsangan (stimulus) yang bersifat fisika dan kimia. Bau-bau yang terlarut di dalam air dapat merangsang reseptor pada organ. Umpan yang digunakan untuk kegiatan penangkapan bubu adalah ikan petek segar yang sudah mati.

Bubu dapat diaplikasikan untuk menangkap hewan-hewan krustasea seperti rajungan, lobster dan kepiting yang bergerak dengan menggunakan kakinya pada dasar perairan sesuai dengan kontstruksi dari alat tangkapnya. Daerah penangkapan bubu adalah perairan yang mempunyai dasar perairan berlumpur maupun dasar pasir ataupun daerah berkarang tergantung yang menjadi tujuan penangkapan. Penentuan daerah penangkapan untuk perikanan bubu tidak seperti halnya menentukan daerah penangkapan untuk ikan pelagis besar seperti tuna dan ikan pelagis pada umumnya, dimana harus selalu memperhitungkan faktor oseanografi, kelimpahan plankton dan faktor lainnya yang berhubungan. Daerah penangkapan rajungan adalah wilayah pantai dengan dasar pasir, pasir lumpur, dan juga di laut. 


\section{JOURNAL OF MANAGEMENT OF AQUATIC RESOURCES \\ Volume 2, Nomor 2, Tahun 2013, Halaman 243-248 \\ Online di : http://ejournal-s1.undip.ac.id/index.php/maquares}

Struktur ukuran berat tubuh dari rajungan selama penelitian di Perairan Rembang tersaji pada Gambar 1.

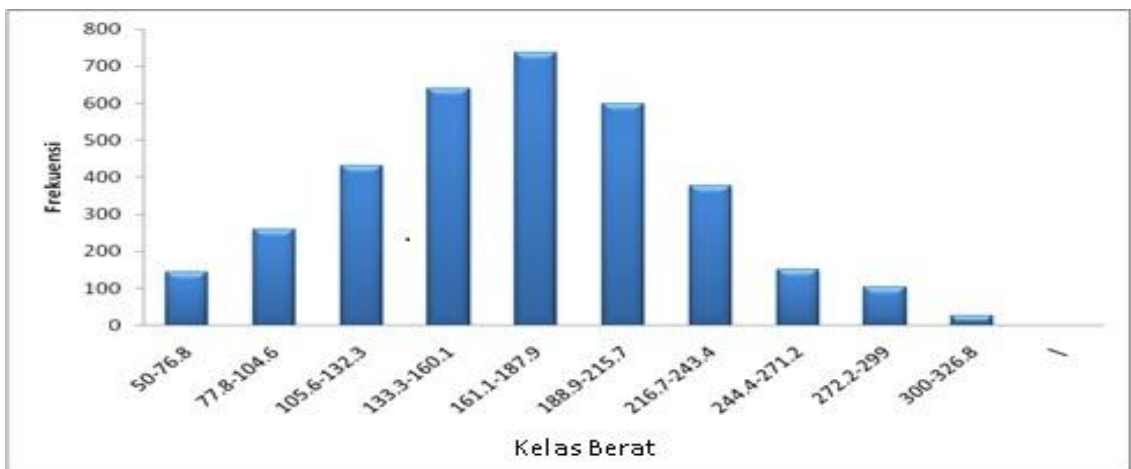

Sumber : Data hasil penelitian, TPI Tanjung Sari (2012).

Gambar 1. Histogram Struktur Ukuran Rajungan.

Pada Gambar 1, persebaran ukuran rajungan dari struktur ukuran membentuk satu kurva dimana ukuran rajungan yang jumlah tertangkapnya paling sedikit yaitu pada kisaran kelas 300-326,8 gr tertangkap dengan jumlah atau frekuensi 27 ekor. Sedangkan jumlah rajungan yang tertangkap paling banyak adalah pada kisaran ukuran kelas 161,1-187,9 gr dengan jumlah 736 ekor.

Produktivitas suatu alat tangkap dapat dinyatakan dengan CPUE. Nilai CPUE diperoleh dengan menjumlahkan seluruh jumlah produksi bubu setiap hari dibagi dengan jumlah kapal yang berangkat melaut. Data produksi dan CPUE dapat dilihat pada Tabel 1.

Tabel 1. Produksi dan CPUE bubu selama Penelitian

\begin{tabular}{cccc}
\hline Hari ke- & Total tangkapan $(\mathrm{kg})$ & Jumlah kapal & CPUE \\
\hline 1 & 25.21 & 5 & 5.04 \\
2 & 24.33 & 5 & 4.87 \\
3 & 24.26 & 5 & 4.85 \\
4 & 27.46 & 5 & 5.49 \\
5 & 24.06 & 5 & 4.81 \\
6 & 25.21 & 5 & 5.04 \\
7 & 21.11 & 5 & 4.22 \\
8 & 24.81 & 5 & 4.96 \\
9 & 26.21 & 5 & 5.24 \\
10 & 25.86 & 5 & 5.17 \\
11 & 24.71 & 5 & 4.94 \\
12 & 23.46 & 5 & 4.69 \\
13 & 24.76 & 5 & 4.95 \\
14 & 25.06 & 5 & 5.01 \\
15 & 22.11 & 5 & 4.42 \\
16 & 23.41 & 5 & 4.68 \\
17 & 23.76 & 5 & 4.75 \\
18 & 25.96 & 5 & 5.19 \\
19 & - & - & - \\
20 & - & - & - \\
21 & - & - & - \\
22 & - & - & - \\
23 & 24.71 & 5 & 4.9 \\
24 & 23.76 & 5 & 4.8 \\
25 & 23.56 & 5 & 4.7 \\
26 & 28.76 & 5 & 5.75 \\
27 & 24.46 & 5 & 4.9 \\
28 & 24.76 & 5 & 5.0 \\
\hline
\end{tabular}

Sumber : data hasil penelitian, TPI Tanjung Sari (2012).

Dari hasil tabel 1 menunjukkan bahwa produksi rata-rata mengalami perubahan naik-turun setiap harinya. CPUE yang tertinggi pada hari ke-26 yaitu sebanyak 5,75 kg/trip dengan total produksi $28,76 \mathrm{~kg}$ dan CPUE terendah terjadi pada hari ke-7 yaitu sebesar 4,22 kg/trip dengan total produksi yang didapat dari hasil tangkapan sebanyak 21,11 kg tangkapan. Dengan CPUE rata-rata 4,55 kg/trip dengan rata-rata total produksi $24,65 \mathrm{~kg}$. 
Umpan yang digunakan untuk alat tangkap bubu lipat adalah umpan mati yaitu ikan petek segar, umpan ini biasa digunakan para nelayan bubu untuk menangkap rajungan karena ikan petek memiliki bau yang sangat menyengat. Hal ini berfungsi untuk menarik perhatian dari rajungan yang ingin di tangkap yang memiliki penciuman yang sangat sensitif terhadap bau umpan. Umpan diletakkan ditengah-tengah bagian rangka bubu.Menurut Slack dan Smith (2001), syarat umpan yang baik adalah efektif untuk menarik ikan target, ketersediannya melimpah,mudah untuk disimpan dan diawetkan, dan harganya murah agar operasi penangkapan menguntungkan, sedangkan menurut Martasuganda (2003) mengatakan bahwa umpan yang baik memiliki karakteristik Efektif dalam menarik ikan, mudah diperoleh, murah, mudah disimpan dan, tahan lama.

Monintja dan Martasuganda (1990), menyatakan bahwa terperangkapnya udang, kepiting atau ikan-ikan dasar pada bubu disebabkan oleh beberapa faktor, salah satunya dikarenakan tertarik oleh bau umpan. Penciuman krustasea sangat sensitif dan akurat ketika mereka mencari sumber bau-bauan walaupun bau tersebut telah dikacaukan oleh turbulensi lingkungan pada saat bau tersebut didistribusikan.

Dari hasil penelitian Ramdani (2007), yang melakukan penelitian untuk menentukan umpan yang paling baik dalam menangkap rajungan dengan menggunakan empat umpan yang berbeda yaitu petek segar, petek asin, petek segar campur potongan rajungan, dan petek segar yang diolesi minyak kedelai. Hasil penelitian menunjukkan bahwa bubu dengan umpan ikan petek segar campur potongan rajungan menangkap rajungan dengan jumlah yang lebih banyak dan ukuran yang lebih besar. Hal ini disebabkan karena rajungan yang berukuran besar memiliki sifat agresivitas yang tinggi sehingga mengabaikan bau / substansi kimia yang dikeluarkan oleh rajungan yang telah mati.

\section{Struktur dan frekuensi ukuran hasil tangkapan bubu}

Struktur kelas ukuran berat tubuh tertinggi dari rajungan selama penelitian di Perairan di Rembang dominasi kelas 161.1-187.9 gr yaitu sebanyak 736 ekor dan terendah oleh kelas 300-326.8 gr dengan sebanyak 27 ekor rajungan dengan rata-rata tangkapan sebanyak 115,76 ekor selama penelitian.

Distribusi ukuran rajungan selama penelitian di TPI Tanjung Sari Perairan Kabupaten Rembang membentuk satu kurva distribusi normal sehingga dapat diduga bahwa rajungan merupakan kumpulan satu kohort. Menurut Saputra (2009), definisi kohort adalah sekelompok rajungan atau ikan dari satu spesies yang anggotanya kurang lebih sama umurnya dan menghuni suatu wilayah perairan tertentu. Pada penelitian ini satu kohort rajungan, berarti rajungan yang ditetapkan pada suatu periode tertentu pada bulan April dan Mei 2012 di Perairan Rembang, ditemukan sebanyak 3473 ekor. Jumlah anggota kohort akan mengalami pengurangan dengan bertambahnya waktu. Kecepatan pengurangan anggota kohort tersebut bergantung pada kondisi perairan dan laju eksploitasinya.

Berat rajungan dan kelimpahan hasil tangkapan juga sangat di pengaruhi oleh fakor jenis umpan yang digunakan serta bobot dari umpannya dimana jenis umpan yang digunakan dalam penelitian ini adalah ikan petek segar yang sudah mati serta bobot umpan $<1 \mathrm{~kg}$ dengan lama perendaman 1 hari.

\section{Produktivitas alat tangkap bubu}

Perkembangan produktivitas hasil tangkapan bubu selama penelitian dapat dikatakan sangat sedikit, Produksi tertinggi yaitu sebesar $28,76 \mathrm{~kg}$ dan produksi yang terendah sebesar $21,11 \mathrm{~kg}$, dengan rata-rata total produksi 24,65 kg dengan total hasil tangkapan sebanyak 3473 ekor dalam kurun waktu 1 bulan selama kegiatan penelitian.

Produksi alat tangkap bubu dari hasil penelitian mengalami perubahan naik-turun setiap harinya, begitu juga dengan nilai CPUE setiap harinya, CPUE yang tertinggi pada hari ke-26 yaitu sebanyak 5,75 kg/trip dengan CPUE terendah terjadi pada hari ke-7 yaitu sebesar 4,22 kg/trip. Dengan CPUE rata-rata 4,55 kg/trip Pengaruh kondisi lingkungan dan oseanografi memegang peranan yang signifikan dalam perubahan CPUE, sedangkan angin dan hujan berpengaruh langsung terhadap kegiatan dan hasil tangkapan.

Naik-turunnya nilai produksi hasil tangkapan dipengaruhi oleh letak fishing ground. Penentuan letak fishing ground oleh para nelayan biasanya mereka menggunakan feeling dan pengalaman mereka di laut. Alat tangkap bubu termasuk jenis alat tangkap yang bisa beroperasi sepanjang tahun. Namun pada musim barat yaitu terjadi ombak dan angin sehingga nelayan bubu yang melakukan penangkapan akan berkurang, karena nelayan lebih memilih untuk tidak melaut pada saat musim barat.

\section{Saran}

Saran yang dapat diberikan dari penelitian ini adalah Perlu diadakan pendataan produksi dan trip hasil tangkapan bubu lipat sehingga perkembangan eksploitasinya dapat terus di pantau pada setiap tahunnya dan perlu dilakukan penelitian yang mendetail tentang rajungan untuk mengetahui musim dan daerah pemijahan. 
Ucapan Terimakasih

Pada kesempatan ini penulis mengucapkan banyak terimakasih kepada Dr. Ir. Suradi Wijaya Saputra, MS dan Ir. Anhar Solichin, M.Si yang telah membantu dalam penyusunan penulisan ini, serta teman-teman yang turut berpartisipasi dalam penelitian.

\section{DAFTAR PUSTAKA}

Martasuganda, S. 2003. Bubu (Traps). Serial Teknologi Penangkapan Ikan Berwawasan Lingkungan. Fakultas Perikanan dan Ilmu Kelautan. Institut Pertanian Bogor. Bogor.52 hal.

Monintja. Daniel. R. 2006. Teknologi Perikanan Tangkap yang Bertanggungjawab. Pemanfaatan Sumberdaya Perikanan dan Ilmu Kelautan ITB Bogor : Bogor.

Monintja, D.R. dan S. Martasuganda.1990. Teknologi Pemanfaatan Sumberdaya Hayati Laut II. Proyek Peningkatan Perguruan Tinggi. Institut Pertanian Bogor. Bogor. 85 hal

Ramdani, D. 2007. Perbandingan Hasil Tangkapan Rajungan pada Bubu Lipat dengan Menggunakan Umpan yang Berbeda. [Skripsi]. Bogor: Departemen Pemanfaatan Sumberdaya Perikanan. Fakultas Perikanan dan Ilmu Kelautan. Institut Pertanian Bogor. No : -

Slack, R.J.S. 2001. Fishing With Traps and Pots. FAO Training Series. Italy: FAO

Saputra, S.W. 2009. Buku Ajar Berbasis Riset Dinamika Populasi Ikan. Badan Penerbit Universitas Diponegoro: Semarang. 